\title{
Food-pellet size directs hoarding in rats
}

\author{
IAN Q. WHISHAW, LAURA NICHOLSON, and SCOTT D. ODDIE \\ University of Lethbridge, Lethbridge, Alberta, Canada
}

\author{
(J. D. Read, Sponsor)
}

\begin{abstract}
Rats ranging in age from 17 days of age to adulthood were presented with food pellets of different sizes ( 20 to $500 \mathrm{mg}$ ) in a conventional hoarding apparatus. Food-pellet size influenced the rat's motor behavior. The rats ate small food pellets as they retrieved them, sat back on their haunches to eat medium size pellets, and hoarded the large pellets to the covered enclosure in the hoarding box. These behavioral patterns appeared in rats as early as 17 days of age. The most obvious age-related difference was that, in the infant rats, size/behavior relations were shifted downward from adult values. The infant rats were more likely to hoard smaller food pellets than were the adult rats. Rats of all ages used different motor patterns when searching and when hoarding. They walked to get food and galloped back with it. These novel findings suggest that perioral contact with the food pellet elicits, from among a number of movement sequences, movement patterns that are dependent on food-pellet size. The findings are relevant to the optimal foraging theory and are discussed with respect to interspecies and intraspecies competition.
\end{abstract}

Food hoarding is an easily observed feature of laboratory-rat behavior (Wolfe, 1939). In addition to hoarding food pellets, rats will hoard water pledges (Bindra, 1947), nesting material (Calhoun, 1962) and junk objects (McCain, Garrett, Reed, Mead, \& Kuenstler, 1964; Ross, Smith, \& Nienstedt, 1950; Ross, Smith, \& Woessner, 1955; Wallace, 1978). They even attempt to hoard body parts, such as their tail or paw (Licklider \& Licklider, 1950; Wallace, 1976). A good deal of research has concentrated on the nature of the environment that elicits hoarding (Bindra, 1948; Miller \& Viek, 1944), the effects of food deprivation (Morgan, Stellar, \& Johnson, 1943; Porter, Webster, \& Licklider, 1950; Stellar \& Morgan, 1943), environmental temperature (Fantino \& Cabanac, 1980; McCleary \& Morgan, 1946) and the familiarity of the objects (Wallace, 1979), but little attention has been directed toward study of the features of objects that are hoarded.

In the present study, we examined the effects of foodpellet size on food hoarding. The experiments were performed using commercially obtained food pellets of fixed sizes. In addition to recording hoarding behavior, we also recorded how the rats ate food pellets of different sizes and where they ate them. The study shows that food-pellet size is an important determinant in eating and hoarding behavior.

\section{METHOD}

\section{Subjects}

The subjects were 15 adult, Long-Evans male (300-350 g) rats and 6 infant rats (studied between the ages of 15 and 40 days). The adult rats were housed in pairs and the infant rats were housed in a group

This research was supported by a grant from the Natural Sciences and Engineering Research Council of Canada. Correspondence may be sent to I. Q. Whishaw, Department of Psychology, University of Lethbridge, Lethbridge, Alberta T1K 3M4, Canada. maternity cage. Animal-housing lighting was on a 12:12-h light:dark cycle, and all testing was done in the daylight portion of the cycle.

\section{Apparatus}

The rats were tested in a hoarding box consisting of a wire-mesh home cage, similar to the cage in which they were housed in the laboratory, and a Plexiglas alley that led to the food source. The mesh cage was $21 \mathrm{~cm}$ wide, $25 \mathrm{~cm}$ high, and $19 \mathrm{~cm}$ long, with a metal roof. One side of the cage was Plexiglas so that the behavior of the rat, while in the cage, could be observed. A 6-cm-wide $\times 7.5-\mathrm{cm}$-high door allowed access to the alley. The alley was $106 \mathrm{~cm}$ long, $25 \mathrm{~cm}$ wide, and $26 \mathrm{~cm}$ high. Food was introduced into the alley through a $1.5-\mathrm{cm}$-diameter hole, located on the wall at floor level, at the end of the alley farthest from the home cage.

\section{Food}

Eight different-sized food pellets (Bioserve Inc., Frenchtown, NJ) weighing $20,37,75,94,190,300$, and $500 \mathrm{mg}$ were used. Hereafter, the pellets are referred to as sizes 1 to 8 .

\section{Procedure}

During the first week, the adult rats were placed on a food-deprivation schedule that reduced them to about $90 \%$ body weight. They were fed a measured amount of food once a day, in addition to the food that they received in the hoarding tests. The infant rats were not food-deprived. We habituated the rats to the hoarding apparatus over 1 week by placing them in it in pairs for $15 \mathrm{~min}$ a day. Food pellets of different sizes were scattered on the floor at the end of the alley for the rats to eat or retrieve. During the second week, food pellets were presented (for the rats to take) one at a time at the hole at the end of the alley. By the end of this 2-week period, the rats readily went to the end of the alley and retrieved the food pellets. The infant rats were given no special training, but were allowed to explore the alley and search for food in it. For the formal test, each rat was placed individually into the home cage. When it walked to the end of the alley, it received a single food pellet. During the course of the test, each rat was given 40 food pellets (five pellets of each of the eight sizes). The behavior of the rat after each food presentation was given was one of the following three classifications: (1) Eat-If a rat accepted a food pellet and ate it without turning laterally away or moving backward from the food source, the behavior was designated as "Eat." (2) Sit-If a rat accepted a food pellet and then turned away from the food source, or stepped backward with the food and adopted a sitting posture to eat it, the behavior was given the classification "Sit." (3) Hoard-If a rat took the food pellet in its 
mouth and transported it to the home cage at the end of the alley, the behavior was classified as "Hoard." The selection of food-pellet size on each trial was indicated on the screen of a monitor connected to an Apple II + microcomputer. The behaviors of the rat with the food were given the following numerical designations: Eat $=1$, Sit $=2$, Hoard $=3$. After each trial, the appropriate number was entered into the computer via the keyboard, then the computer indicated the size of the next food pellet (generated by a random number generating program). After each rat was tested, the computer printed a summary of the rat's performance, indicated the rat's mean score, and presented a graphic display of its performance. The microcomputer requested comments concerning the rat's behavior, which then were printed at the end of the data summary.

Travel speed of a rat approaching the food source and leaving the food source was measured using photocells that triggered a clock program on the microcomputer. Measures were taken on each of five trials as the rats hoarded size 8 (large) food pellets.

\section{RESULTS}

A summary of the behaviors elicited from the adult rats as a function of food-pellet size is shown in Figure 1. The adult rats swallowed the smallest food pellets as soon as they picked them up. They grasped the intermediate-sized food pellets in their mouth, transferred them to their paws, then sat back on their haunches to eat them. Then they carried the largest food pellets back to the home cage, where they ate them in a sitting posture. This pattern of behavior was identical in every one of the adult rats tested. An analysis of variance showed that there was no significant effect of behavior $[F(2,28)=.29, p>.75]$ or pellet size $[F(7,98)=1, p=.43]$, but the behavior by pellet interaction was highly significant $[F(14,196)=71.86$, $p=.00001]$. By Day 17, the behavior of the infant rats was similar to that of the adult rats. However, they hoarded more small pellets and medium-sized pellets than did the adult rats. As they aged, their behavior began to approximate that of the adult rats. As was the case for the adult rats, there was a significant interaction between

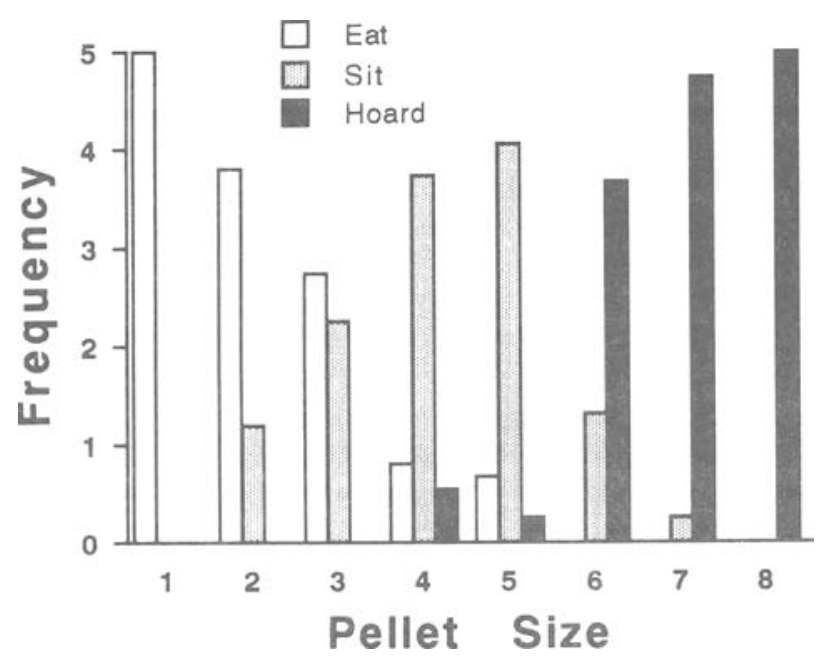

Figure 1. Effect of food size on behavior. Eat $=$ food swallowed as it was grasped. Sit = food eaten after rat adopted a sitting posture. Hoard $=$ food transported to the home cage. Note that small pellets were swallowed, medium-sized pellets were eaten from a sitting posture, and large pellets were hoarded. the size of food pellet hoarded and the number hoarded $[F(7,14)=19.53, p<.001]$.

The running speed of 5 rats was compared between their approaches to the food source and their returns with size 8 food pellets. Their mean approach speed over a 1-m test distance was $.94 \mathrm{sec}$, and their mean return speed was $.49 \mathrm{sec}-\mathrm{a}$ difference that was significant $(p<.001)$. Generally, the rats walked as they approached the food source, often making pauses, but they galloped as they returned.

\section{DISCUSSION}

This study describes a novel finding concerning the food-hoarding behavior of laboratory rats. Their behavior is influenced by food-pellet size. As the size of a food pellet increased so did the probability that the food pellet would be hoarded. Other motor behaviors also were influenced by food-pellet size. When rats encountered very small food pellets, they grasped them by mouth and swallowed them. Intermediatesized food pellets were grasped in the mouth, then the rat transferred them to its paws and sat back on its haunches to eat them. Thus, food, depending upon its size, could elicit a number of motor behaviors.

These observations may be relevant not only for studying hoarding by laboratory rats but for understanding the motor behavior of foraging rats in a more general context. With respect to the optimal foraging theory (Pyke, Pulliam, \& Charnov, 1977), an animal at risk to predation can decrease its exposure if it can hoard an optimal amount of food to a secure location for consumption. The food-pellet/behavior relation may define what is optimal. Nevertheless, some of the rat's behavior also may serve to protect it from conspecifics, which have a propensity to steal food (Whishaw \& Tomie, 1987, 1988). We feel that the latter hypothesis should receive particular attention. When we have presented rats with large numbers of small food pellets, we have found that they remain to consume them on site. Thus, where food objects are small (e.g., grain stores) or medium-sized, rats remain exposed to both predation and theft. Rapid eating of small pieces of food, and dodging with intermediate-sized pieces of food (Whishaw, 1988; Whishaw \& Tomie, $1987,1988)$, are behaviors that are adaptively used with conspecifics, but not with predators.

Finally, we have speculated about the stimulus feature of food that instructs motor patterns. It is possible that this is in some way related to body size. This idea derives from the observation that the infant rats, when they begin hoarding, are far more likely to hoard small food pellets than are adult rats. Thus, mouth opening could serve as a sufficient stimulus. It also is possible that infant rats are more likely to hoard small food items because infant rats are more vulnerable than adult rats. These possibilities could be examined in future research.

\section{REFERENCES}

BINDRA, D. (1947). Water hoarding in rats. Journal of Comparative \& Physiological Psychology, 40, 149-156.

BindRA, D. (1948). The nature of motivation for hoarding food. Journal of Comparative \& Physiological Psychology, 41, 211-218.

Calhoun, J. B. (1962). The ecology and sociology of the Norway rat (Public Health Service Publication No. 1008). Washington, DC: U.S. Government Printing Office.

Fantino, M., \& Cabanac, M. (1980). Body weight regulation with a proportional hoarding response in the rat. Physiology \& Behavior, 24, 939-942.

Licklider, L. C., \& Licklider, J. C. R. (1950). Observation on the hoarding behavior of rats. Journal of Comparative \& Physiological Psychology, 43, 129-134.

McCain, G., Garrett, B. L., Reed, C., Mead, G., \& Kuenstler, R. (1964). Effects of deprivation on hoarding of objects other than the deprived material. Animal Behaviour, 12, 409-415.

MCCleary, R. A., \& Morgan, C. T. (1946). Food hoarding in rats as a function of environmental temperature. Journal of Comparative Psychology, 39, 371-378. 
Miller, G. A., \& VieK, P. (1944). An analysis of the rat's response to unfamiliar aspects of the hoarding situation. Journal of Comparative Psychology, 37, 221-231.

Morgan, C. T., Stellar, E., \& Johnson, O. (1943). Food deprivation and hoarding in rats. Journal of Comparative Psychology, 35, 275-295.

Porter, J. H., Webster, F. A., \& Licklider, J. C. R. (1950). The influence of age and food deprivation upon the hoarding behavior of rats. Journal of Comparative \& Physiological Psychology, 44, 300-309.

Pyke, G. H., Pulliam, R. H., \& Charnov, E. L. (1977). Optimal foraging: A selective review of theory and tests. Quarterly Review of Biology, 52, 137-154.

Ross, S., Smith, W. I., \& Nienstedt, C. W., Jr. (1950). The hoarding of non-relevant material by the white rat. Journal of Comparative \& Physiological Psychology, 43, 217-225.

Ross, S., SMITH, W. I., \& WoEssner, B. L. (1955). Hoarding: An analysis of experiments and trends. Journal of General Psychology, 52, 307-326.

Stellar, E., \& Morgan, C. T. (1943). The roles of experience and deprivation in the onset of hoarding behavior in the rat. Journal of Comparative Psychology, 36, 47-55.
Wallace, R. J. (1976). Tail-hoarding in the albino rat. Animal Behaviour, 24, 176-180.

WALLACE, R. J. (1978). Hoarding of inedible objects by albino rats. Behavioral Biology, 23, 409-414.

WALLACE, R. J. (1979). Novelty and partibility as determinants of hoarding in the albino rat. Animal Learning \& Behavior, 7, 549-554.

Whishaw, I. Q. (1988). Food wrenching and dodging: Use of action patterns for the analysis of sensorimotor and social behavior in the rat. Journal of Neuroscience Methods, 24, 169-178.

WhISHAw, I. Q., \& ToMiE, J. (1987). Food wresting and dodging: Strategies used by rats (Rattus norvegicus) for obtaining and protecting food from conspecifics. Journal of Comparative Psychology, 101, 202-209.

Whishaw, I. Q., \& ToMie, J. (1988). Food wresting and dodging: A neuroethological test of cortical and dopaminergic contributions to sensorimotor behavior. Behavioral Neuroscience, 102, 110-123.

WoLFE, J. B. (1939). An exploratory study in food-storing in rats. Journal of Comparative Psychology, 28, 97-101.

(Manuscript received June 29, 1988.) 